\title{
PERBEDAAN RADIOPASITAS ANTARA BAHAN OBTURASI SEALER BERBAHAN DASAR KALSIUM HIDROKSIDA DAN EPOKSI RESIN DENGAN TEKNIK RADIOGRAFI CONE BEAM COMPUTED TOMOGRAPHY (CBCT)
}

\author{
Rismeiza Hajir *, Resti Iswani**, Widyawati*** \\ **Bagian Radiologi, FKG Universitas Baiturahmah \\ ***Bagian Konservasi, FKG Universitas Baiturahmah \\ Jl. Raya By. Pass KM. 14 Sei Sapih, Padang \\ Email: rismeiza_hajir@yahoo.com
}

$\overline{\text { KATA KUNCI }}$

Radiopasitas, sealer obturasi berbahan dasar kalsium hidroksida, sealer berbahan dasar epoksi resin

\begin{abstract}
ABSTRAK
Penyakit gigi dan mulut di Indonesia terutama karies masih banyak diderita. Salah satu cabang kedokteran gigi yang menangani perawatan gigi dikenal dengan perawatan Endodontik. Perawatan saluran akar merupakan bagian dari perawatan endodontik yang salah satu prosedurnya terdiri dari obturasi saluran akar. Bahan obturasi saluran akar yang digunakan hingga saat ini adalah gutta percha yang dalam aplikasinya harus dikombinasikan dengan sealer saluran akar. Syaratsyarat sealer salah satunya adalah tingkat radiopasitas. Penelitian ini bertujuan untuk mengetahui perbedaan radiopasitas antara sealer obturasi berbahan dasar kalsium hidroksida dengan sealer berbahan dasar epoksi resin pada teknik $C B C T$. Jenis penelitian ini adalah penelitian eksperimental laboratorium.Analisa statistik menggunakan independent sample $t$-tes diperoleh nilai $\mathrm{p}=0,000<0,05$ artinya terdapat perbedaan radiopasitas antara sealer obturasi berbahan dasar kalsium hidroksida dengan sealer berbahan dasar epoksi resin pada teknik $C B C T$ secara signifikan dimana nilai radiopasitas tertinggi terdapat pada sampel sealer berbahan dasar epoksi resin.
\end{abstract}

\section{KEYWORDS}

radiopacity, calcium hydroxide-based obturation sealer, epoxy resin-based sealer

\begin{abstract}
Dental and oral disease in Indonesia, especially caries is still commonly found in Indonesia. One of the fields in dentistry that studied about root canal treatment is endodontic. Root canal treatment is one of the endodontic treatments included obturation as one of the procedures. The material for root canal obturation that has been used until todays is gutta percha which in its application has to be combined with sealer. One of the requirements for a good sealer is that the level of radiopacity. This study purposed to find out the radiopacity difference between calcium hydroxide-based sealer with epoxy resinbased sealer in CBCT radiograph technique. The research was experimental laboratory, with independent sample t-test analytic with $p$ value $=0.000<0.05$ which means that there was a significant difference in radiopacity between calcium hydroxide-based sealer with epoxy resin-based sealer in CBCT technique where the highest level of radiopacity was found in sealer sample with epoxy resin-based sealer.
\end{abstract}

\section{PENDAHULUAN}

Penyakit gigi dan mulut di Indonesia, terutama karies dan penyakit periodontal masih banyak diderita, baik oleh anak-anak maupun usia dewasa. Sebagian besar masalah kesehatan gigi dan mulut 
sebenarnya dapat dicegah. Kesehatan mulut tidak sepenuhnya bergantung pada perilaku seseorang. Banyak yang dapat dilakukan untuk mengurangi dan mencegah penyakit gigi dan mulut dimulai dari pencegahan pada diri sendiri, masyarakat dan perawatan oleh tenaga professional ${ }^{1}$

Salah satu cabang kedokteran gigi yang dapat menangani tentang perawatan gigi, gusi dan jaringan tulang di sekelilingnya dikenal dengan perawatan Endodontik. Endodontik adalah cabang ilmu kedokteran gigi yang berhubungan dengan etiologi pencegahan, diagnosis dan terapi terhadap penyakit yang mengenai pulpa gigi, akar gigi dan jaringan periapikal ${ }^{2}$.

Perawatan saluran akar merupakan bagian dari perawatan endodontik. Ada tiga tahap perawatan saluran akar yang harus dilakukan yaitu preparasi, sterilisasi dan obturasi saluran akar. Obturasi saluran akar merupakan salah satu tahapan penting dalam keberhasilan suatu perawatan saluran akar yang bertujuan untuk mendapatkan suatu kondisi yang disebut fluid tight seal pada bagian sepertiga apikal. Fluid tight seal adalah kemampuan untuk mencegah merembesnya cairan jaringan kedalam saluran akar ${ }^{3}$.

Bahan obturasi saluran akar yang digunakan hingga saat ini adalah gutta percha yang dalam aplikasinya harus dikombinasikan dengan sealer saluran akar. Fungsi utama dari sealer yaitu untuk mengisi celah yang terjadi antara gutta percha dan dinding saluran akar baik ke arah apikal maupun lateral sehingga mencegah terjadinya kebocoran apikal ${ }^{4}$.

Syarat-syarat sealer adalah biokompatibilitas, tidak terjadi pengkerutan pada saat pengerasan, dapat diukur waktu pengerasannya, melekat ke dinding kanal dengan baik, radiopak, tidak mewarnai gigi, mampu dilarutkan dengan baik menggunakan bahan pelarut, tidak larut oleh cairan jaringan pada mulut, bakteriostatik, dan dapat menutup bagian apikal, lateral, dan koronal akar gigi ${ }^{5}$.

Bahan dasar sealer antara lain resin epoksi yang digunakan untuk perawatan endodontik, salah satu contohnya yaitu AH26 ( De Trey, Zurich, Switzerland), tetapi semen ini sudah mulai digantikan dengan dengan $A H$ plus dan Topseal, karena produksi sulfida perak hitamnya yang dapat menyebabkan diskolorisasi pada gigi. Pada AH plus juga ditambahkan oksida bismuth untuk radiopasitasnya. ${ }^{6}$

Sealer berbahan dasar kalsium hidroksida yang paling populer adalah sealer saluran akar Caciobiotic (CRCS) (Hygenic, Akron, Ohio, Amerika Serikat) dan Sealapex (Kerr, Romulus, Michigan, A.S). CRCS mengandung zinc okside eugenol serta kalsium hidroksid. Sealapex adalah resin polimerik yang mengandung kalsium hidroksid ${ }^{7}$. 


\section{METODE}

Penelitian ini merupakan penelitian eksperimental laboratorium dengan rancangan posttesst only with control group design.

\section{Cara Kerja}

\section{Tahap Persiapan Sampel}

Memotong cetakan sealer dengan diameter $3 \mathrm{~mm}$ dengan panjang $3 \mathrm{~mm}$ menjadi cincin plastik sebanyak 10 buah. Kemudian dibagi menjadi 2 kelompok masing - masing kelompok berjumlah 5 sampel.

\section{Tahap Pengisian}

Kelompok pertama sealer berbahan dasar resin epoksi dicampurkan antara base dan katalis. Perbandingan antara base dan katalis yang digunakan sesuai petunjuk pabrik. Base dan katalis dicampur menggunakan Agate spatel dan diaduk selama 30 detik sehingga diperoleh konsistensi yang kental dan dimasukkan kedalam cincin plastik menggunakan plastis instrumen.

Kelompok kedua sealer berbahan dasar kalsium hidroksida (calplus) dimasukkan kedalam saluran akar menggunakan syringe kemasan kalsium hidroksida (calplus). Kemudian lakukan pengambilan foto menggunakan ronsen foto $C B C T$ dibagian radiologi Universitas Trisakti.

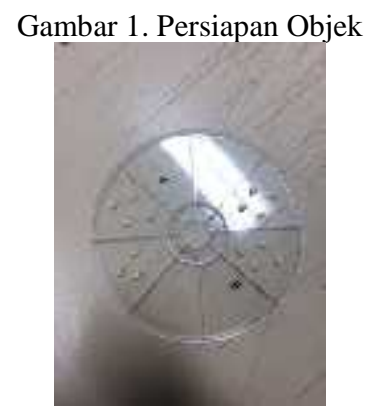

Gambar 2. Objek diberi paparan radiasi

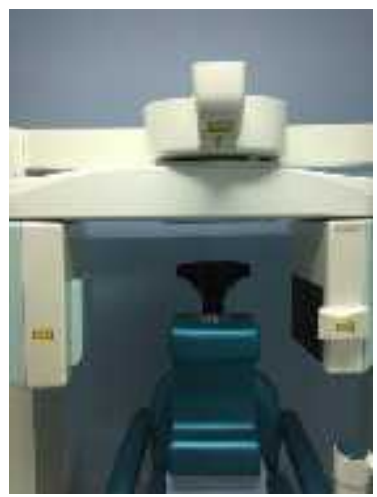

Gambar 3. Hasil poto dapat dilihat dikomputer

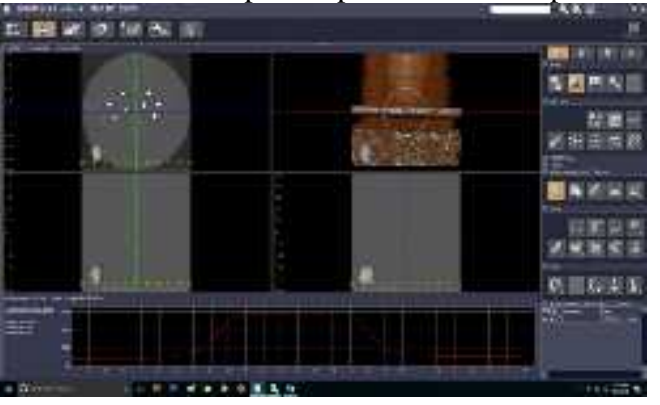

Kemudian buka I-dixel software image untuk melihat hasil foto ronsen.

\section{Analisis Data}

Hasil radiopasitas yang didapatkan dari sealer berbahan dasar resin epoksi dan sealer berbahan dasar kalsium hidroksida pada teknik radiografi $\mathrm{CBCT}$ adalah data kuantitatif yang diperoleh dari hasil pengukuran skala derajat keabuan sehingga didapatkan suatu data berskala rasio.Uji normalitas menggunakan Shapiro Wilk untuk mengetahui data tersebut terdistribusi normal. Data dianalisis dengan uji statistik Independent t-test dilakukan dengan menggunakan perangkat SPSS versi 13.

\section{HASIL}

Penelitian perbedaan radiopasitas antara sealer obturasi berbahan dasar kalsium 
Hajir : Perbedaan radiopasitas antara bahan obturasi...

hidroksida dengan sealer berbahan dasar epoksi resin pada teknik $C B C T$ Laboratorium FKG Baiturrahmah dan bagian Radiologi Universitas Trisakti pada bulan Agustus
2017 - Maret 2018. Sampel pada penelitian ini adalah 5 spesimen sealer berbahan dasar resin epoksi dan 5 spesimen sealer berbahan dasar kalsium hidroksida.

Tabel 1. Radiopasitas Antara Sealer Obturasi Berbahan Dasar Kalsium Hidroksida dan Sealer Berbahan Dasar Epoksi Resin Pada Teknik CBCT

\begin{tabular}{|c|c|c|c|c|c|c|c|}
\hline \multirow{2}{*}{$\begin{array}{c}\text { Sampel } \\
\text { (A) }\end{array}$} & \multicolumn{3}{|c|}{ Radiopasitas } & \multirow{2}{*}{$\begin{array}{c}\text { Sampel } \\
\text { (B) }\end{array}$} & \multicolumn{3}{|c|}{ Radiopasitas } \\
\hline & Pandangan & Nilai & Rerata & & Pandangan & Nilai & Rerata \\
\hline \multirow{3}{*}{ A1 } & axial & 5041 & \multirow{3}{*}{4829} & \multirow{3}{*}{ B1 } & Axial & 5921 & \multirow{3}{*}{5795} \\
\hline & coronal & 5069 & & & Coronal & 5672 & \\
\hline & sagital & 4379 & & & Sagital & 5791 & \\
\hline \multirow{3}{*}{ A2 } & axial & 5204 & \multirow{3}{*}{5042} & \multirow{3}{*}{ B2 } & Axial & 5076 & \multirow{3}{*}{5393} \\
\hline & coronal & 4996 & & & Coronal & 5312 & \\
\hline & sagital & 4925 & & & Sagital & 5791 & \\
\hline \multirow{3}{*}{ A3 } & axial & 5063 & \multirow{3}{*}{4815} & \multirow{3}{*}{ B3 } & Axial & 5277 & \multirow{3}{*}{5620} \\
\hline & coronal & 5035 & & & Coronal & 5795 & \\
\hline & sagital & 4348 & & & Sagital & 5788 & \\
\hline \multirow{3}{*}{ A4 } & axial & 5212 & \multirow{3}{*}{4875} & \multirow{3}{*}{ B4 } & Axial & 5793 & \multirow{3}{*}{5752} \\
\hline & coronal & 5035 & & & Coronal & 5672 & \\
\hline & sagital & 4380 & & & Sagital & 5791 & \\
\hline \multirow{3}{*}{ A5 } & axial & 4996 & \multirow{3}{*}{5001} & \multirow{3}{*}{ B5 } & Axial & 5821 & \multirow{3}{*}{5760} \\
\hline & Coronal & 5035 & & & Coronal & 5672 & \\
\hline & Sagital & 4956 & & & Sagital & 5788 & \\
\hline
\end{tabular}

Ket : $\mathrm{A}=$ sealer kalsium hidroksid

$\mathrm{B}=$ sealer resin epoksi

Pada tabel 1 dilihat hasil radiopasitas antara sealer obturasi berbahan dasar kalsium hidroksida dan sealer berbahan dasar epoksi resin pada teknik $C B C T$. Dilihat dari nilai rerata yang memiliki nilai radiopasitas paling tinggi adalah pada sampel sealer berbahan dasar epoksi resin. Berdasarkan data hasil penelitian yang diperoleh, selanjutnya data dianalisis secara statistik menggunakan independent sample-t test untuk melihat apakah terdapat perbedaan radiopasitas antara sealer obturasi berbahan dasar kalsium hidroksida dengan sealer berbahan dasar epoksi resin pada teknik $C B C T$ menggunakan program statistik SPSS for Window 13.0. Syarat untuk melakukan Independent t-test adalah data harus terdistribusi normal, maka dilakukan uji normalitas menggunakan uji Saphiro-Wilk.

Tabel 2. Uji Normalitas Radiopasitas Antara Sealer Obturasi Berbahan Dasar Kalsium Hidroksida dan Sealer Berbahan Dasar Epoksi Resin Pada Teknik CBCT

\begin{tabular}{llcccc}
\hline \multirow{2}{*}{ Kelompok } & $\begin{array}{c}\text { Besar } \\
\text { sampel }\end{array}$ & P-value & Ket. \\
\hline \multirow{2}{*}{ Radiopasitas } & $\begin{array}{l}\text { Sealer berbahan dasar kalsium } \\
\text { hidroksida }\end{array}$ & 5 & 0,271 & Normal \\
\cline { 2 - 5 } & sealer berbahan dasar epoksi resin & 5 & 0,133 & Normal \\
\hline
\end{tabular}


Pada tabel 2 diperoleh nilai $\mathrm{p}>0,05$ artinya data yang diperoleh terdistribusi normal. Dengan demikian syarat untuk melakukan uji statistik Independent t-test terpenuhi sehingga independent sample t-test dapat dilakukan.

Tabel 3. Hasil independent Sample T-test Radiopasitas antara Sealer Obturasi Berbahan Dasar Kalsium Hidroksida dan Sealer Berbahan Dasar Epoksi Resin Pada Teknik CBCT

\begin{tabular}{llcc}
\hline \multirow{2}{*}{ Radiopasitas } & \multicolumn{1}{c}{ Sealer } & Mean & P- Value \\
\cline { 2 - 4 } & $\begin{array}{l}\text { Sealer berbahan dasar Kalsium } \\
\text { hidroksida }\end{array}$ & 4912,4 & 0.000 \\
\cline { 2 - 4 } $\begin{array}{l}\text { Sealer berbahan dasar epoksi } \\
\text { resin }\end{array}$ & 5664 & \\
\hline
\end{tabular}

Tabel 3 menunjukkan hasil independent sample $t$-test dengan perolehan nilai $\mathrm{p}=0,000$ $<0,05$ artinya terdapat perbedaan radiopasitas antara sealer obturasi berbahan dasar kalsium hidroksida dengan sealer berbahan dasar epoksi resin pada teknik $C B C T$ terdapat perbedaan signifikan nilai radiopasitas tertinggi terdapat pada sampel sealer berbahan dasar epoksi resin.

\section{PEMBAHASAN}

Sealer atau semen saluran akar gigi, memiliki peranan penting dalam bidang endodontik terutama pada tahap obturasi dari perawatan saluran akar gigi. Kombinasi penggunaan sealer yang menyertai bahan obturasi inti yang padat (solid core material) seperti gutta percha, yang berfungsi sebagai pelumas bahan obturasi dan mengisi celah diantara permukaan gutta percha dengan dinding saluran akar. Sealer juga berfungsi untuk mengisi celah di antara gutta percha selama kondensasi lateral saat obturasi saluran akar' Syarat-syarat sealer adalah biokompatibilitas, tidak terjadi pengerutan pada saat pengerasan, dapat diukur waktu pengerasannya, melekat ke dinding kanal dengan baik, radiopak, tidak mewarnai gigi, mampu dilarutkan dengan baik menggunakan bahan pelarut, tidak larut oleh cairan jaringan pada mulut, bakteriostatik, dan dapat menutup bagian apikal, lateral, dan koronal akar gigi ${ }^{5}$.

Berdasarkan hasil penelitian terdahulu menyatakan bahwa bahan pengisi saluran akar yang ideal harus memiliki tingkat radiopasitas tertentu yang memungkinkan adanya perbedaan yang jelas antara bahan dan struktur anatomis sekitarnya untuk memudahkan evaluasi kualitas obturasi saluran akar'. Semakin radiopak suatu sealer maka semakin kecil gelembung udara yang terjebak dari hasil obturasi ${ }^{5}$. Bahan dasar sealer antara lain resin epoksi dan sealer berbahan dasar kalsium hidroksida yang sering digunakan untuk perawatan endodontik. Penelitian ini dilakukan untuk mengetahui perbedaan radiopasitas antara sealer obturasi berbahan dasar kalsium 
hidroksida dengan sealer berbahan dasar epoksi resin pada teknik $C B C T$.

Hasil penelitian menunjukkan bahwa rerata radiopasitas yang dihasilkan oleh sealer obturasi berbahan dasar kalsium hidroksida adalah 4912,4 level value sedangkan rerata radiopasitas yang dihasilkan oleh sealer obturasi berbahan dasar epoksi resin adalah 5664 level value. Terdapat perbedaan radiopasitas yang dihasilkan oleh sealer obturasi berbahan dasar kalsium hidroksida dengan sealer berbahan dasar epoksi resin pada teknik $C B C T$ dengan perbedaan rerata sebesar 751,6 level value dengan $\mathrm{p}=0,000$ terdapat perbedaan radiopasitas yang dihasilkan oleh sealer obturasi berbahan dasar kalsium hidroksida dengan sealer berbahan dasar epoksi resin pada teknik CBCT.

Penelitian ini sejalan dengan penelitian yang dilakukan oleh Utami (2014) yang menyatakan bahwa dari kedua kelompok terjadi perbedaan radiopasitas secara signifikan. Sealer berbahan dasar resin epoksi $(6,85 \mathrm{mmAl})$ secara signifikan lebih radiopak daripada sealer berbahan dasar seng oksid eugenol (3,22mmAl). Berdasarkan penelitian Utami (2014) sealer berbahan dasar resin epoksi secara signifikan lebih radioopak daripada sealer berbahan dasar seng oksid eugenol. Sedangkan menurut Tanomaru - filho dkk (2009) sealer berbahan resin (AH-plus) menempati urutan pertama yang memiliki radiopasitas tertinggi dibandingkan dengan sealer berbahan dasar seng oksid eugenol (endomethason), sealer berbahan dasar silikon (roeko seal), sealer berbahan dasar MTA (MTA Fillapex), sealer berbahan dasar resin metakrilat (epiphany) dan sealer berbahan dasar kalsium hidroksid $(\text { Acroseal })^{2,10}$.

Radiopasitas suatu sealer dipengaruhi oleh komposisi bahan kimia, media kontras anorganik, nomor atom, dan densitas pada sealer. Sealer berbahan dasar epoksi merupakan sealer saluran akar memiliki kelebihan yaitu bersifat radiopak, kelarutan rendah, penyusutan kecil, memiliki antibakteri,dan toksisitas rendah (Cohen dan hargreaves, 2010 cit Utami 2014) ${ }^{10}$. Secara umum sealer berbasis epoksi resin memiliki komposisi yaitu bismuth oxide $60 \%$, hexamethylene tetraamine $25 \%$, perak $10 \%$, titanium dioksida 10\%, dan bisphenol-Adiglycidylether. Sealer AH-plus merupakan salah satu bahan sealer yang berbasis epoksi resin memiliki komposisi sebagai berikut Iadamantane amine, N-dibenzyl-5-oksanonandiamine-1,9, TCD-diamineoksida, kalsium tungstat, diepoksid, zirconium oksida, aerosil, bismuth oksida ${ }^{6}$. Pada sealer AH-plus yang berkontribusi dalam radiopasitas yaitu penambahan bismuth oksida, zirconium oksida dan perak untuk meningkatkan radiopasitasnya ${ }^{11}$. Sedangkan sealer berbahan dasar kalsium hidroksida (Calplus) memiliki komposisi yaitu calcium hydroxide, iodoform, silicon oil. Sealer berbahan dasar kalsium hidroksida (Calplus) yang berkontribusi dalam radiopasitas yaitu 
pasta iodoform. (Tanomaru dkk, 2009) mengatakan bahwa penambahan kalsium hidroksida ke dalam bahan pengisian saluran akar akan menurunkan radiopasitas dari bahan tersebut ${ }^{10}$.

Berdasarkan penelitian ini bahan sealer $\mathrm{AH}-$ plus merupakan bahan sealer yang memiliki radiopasitas yang tinggi dibandingkan dengan dengan sealer berbahan dasar kalsium hidroksida (calplus).

\section{SIMPULAN}

Berdasarkan hasil penelitian dapat disimpulkan bahwa terdapat perbedaan radiopasitas antara sealer obturasi berbahan dasar kalsium hidroksida dengan sealer berbahan dasar epoksi resin pada teknik $C B C T$ dimana nilai radiopasitas tertinggi terdapat pada sampel sealer berbahan dasar epoksi resin

\section{DAFTAR PUSTAKA}

1. Putri, H.M Ilmu Pencegahan Penyakit Jaringan Keras dan Jaringan Pendukung Gigi. EGC, Jakarta, hlm. 1. Surya, A, G, N, P. 2014. Efektifitas Sterilisasi Saluran Akar
Menggunakan Teknik Laser dengan Uji Mikroorganisme dalam Saluran Akar. FKG Universitas Mahasaraswati. Skripsi

2. Tanomaru, J. M. G., Duarte, M. A. H., Goncalves, M., Tanomaru-Filho, M., 2009, Radiopacity Evaluation of Root Canal Sealers Containing Calcium Hydroxide and MTA, Braz Oral Res, 23(2):119-23.

3. Yusman R, Mulyawati E, Hadriyanto W, 2013, Perbedaan Kebocoran Apikal Pada Obturasi Saluran Akar Menggunakan Tiga Siler Berbahan Dasar Resin. Jked Gi, Vol 4 No 2 Hlm 122 - 128

4. Mulyawati, E., HNES, M., Sunarintya, S., Handajani, J. 2013. Sifat Fisik Hidroksiapatit Sintesis Kalsit Sebagai Bahan Pengisi Pada Sealer Saluran Akar Resin Epoxy. Majalah kedokteran gigi (Dent, J), Vol. 46, No. 4. Hlm. 207-212.

5. Poedyaningrum, F. 2013. Perbandingan Kebocoran Mikro Sepertiga Apeks Pada Pengisian Saluran Akar Dengan Semen Resin Epoksi Dan MTA. FKG UI. Tesis.

6. Harty, F., J. 1993. Endodonti Klinis, Jakarta: Hipokrates. Hlm 195.

7. Deviyanti, S. 2016. Potensi Diskolorisasi Gigi Dari Penggunaan Sealer Pada Perawatan Saluran Akar Gigi. JITEKGI, 12(1), 1-6.

8. Akcay, I., Ilhan, B., Dundar, N. 2012. Comparison of conventional and digital radiography systems with regard to radiopacity of root canal filling materials. International endodontic journal, 45(8), 730736.

9. Utami, L, H, 2014. Perbedaan Radiopasitas Antara Sealer Berbahan Dasar Resin Epoksi dan Sealer Berbahan Dasar Seng Oksid Eugenol Dengan Teknik Radiografi Periapikal Digital. FKG UGM. Skripsi. 